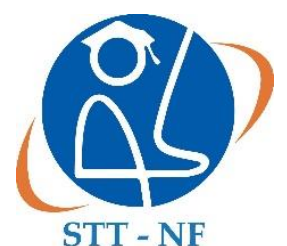

Jurnal Teknologi Terpadu Journal of Integrated Technology

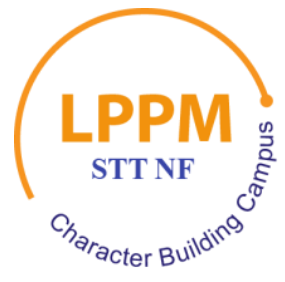

\title{
PERANCANGAN DAN IMPLEMENTASI SISTEM INFORMASI PENJUALAN PADA CV. CIHANJUANG INTI TEKNIK
}

\author{
Badie Uddin $^{1}$, Dedy Suryadi ${ }^{1}$, Siti Maesaroh ${ }^{2}$ \\ ${ }^{1}$ Teknik Komputer, Politeknik TEDC \\ ${ }^{2}$ Komputerisasi Akuntansi, Politeknik TEDC \\ Cimahi, Jawa Barat, Indonesia \\ badie.uddin@gmail.com, suryadidedy45@ngmail.com, sitimaesaroh393@gmail.com
}

\begin{abstract}
The aim of the study is to analyze, design, and implement the information system of sales at CV. Cihanjuang Inti Teknik. The research method which is used in this study is design research with research, including observation, library research, documentation, and questionnaires. Microsoft Visual Basic.NET is used to make this information system and MySQL as database. The information system of sales can solve the problem of CV. Cihanjuang Inti Teknik information system. The certain access is provided by login facilities, which will show particular main menu that is correspond with the authority of office owned by the user. In the data process, the user only enter the data to the information system and system will be process the data to be a information such as sales reports, reports of goods sold, reports customer receivables and accounts receivable aging report. Sales report available in periodic report according to user needs.
\end{abstract}

Keywords: CV. Cihanjuang Inti Teknik, Sales, Design, Information System

\begin{abstract}
Abstrak
Tujuan dari penelitian ini adalah untuk merancang dan mengimplementasikan sistem informasi penjualan pada CV. Cihanjuang Inti Teknik, tentunya hal ini dilakukan setelah melalui proses analisis. Penelitian ini menggunakan metode perancangan dengan instrumen penelitian meliputi kegiatan observasi, kepustakaan, dokumentasi serta kuesioner. Bahasa pemrograman yang digunakan dalam pembuatan sistem informasi penjualan adalah Microsoft Visual Basic.NET sedangkan MySQL digunakan sebagai basis data. Sistem informasi penjualan yang dihasilkan dapat memberikan solusi terhadap masalah pada sistem penjualan yang digunakan pada CV. Cihanjuang Inti Teknik. Hak akses dapat dikendalikan melalui fasilitas login yang menampilkan menu utama sesuai dengan level jabatan yang dimiliki pengguna. Untuk pengolahan data penjualan, pengguna cukup memasukkan data ke dalam sistem informasi kemudian pengolahan data dilakukan oleh sistem sampai dengan pembuatan laporan penjualan, barang terjual, piutang pelanggan, dan aging piutang. Laporan penjualan ini dapat disajikan berdasarkan periodik sesuai dengan kebutuhan pengguna.
\end{abstract}

Kata kunci: CV. Cihanjuang Inti Teknik, Penjualan, Perancangan, Sistem Informasi

\section{PENDAHULUAN}

Di era modern sekarang ini, bidang teknologi informasi mengalami perkembangan yang sangat pesat. Fasilitas teknologi informasi memudahkan masyarakat dalam mengatasi berbagai masalah pada proses kerja agar dapat lebih mudah, efektif dan efisien. Hal ini terlihat juga dengan cepatnya merambah ke dalam dunia usaha. Informasi merupakan aktor yang penting bagi 
perusahaan karena bisa menjadi alat penunjang dalam pengambilan keputusan yang efektif .

CV. Cihanjuang Inti Teknik (CV. CINTEK) merupakan perusahaan manufaktur yang salah satu cabang usahanya bergerak dalam bidang penjualan produk minuman tradisional kemasan instan yaitu bandrek dan bajigur, produk minuman ini cukup dikenal di kalangan masyarakat terutama di daerah Jawa Barat. Kegiatan bagian penjualan pada bidang bisnis ini cukup padat setiap harinya, sedangkan transaksi penjualan masih dilakukan secara manual sehingga sering terjadi kesalahan perhitungan, seperti terjadi selisih antara barang yang terjual dengan catatan. Penggunaan pembukuan manual yang berjalan saat ini membutuhkan waktu yang cukup lama dalam proses penjualan serta pembuatan laporan, sehingga sistem kurang efisien digunakan untuk aktifitas penjualan dan pembuatan laporan. Masih belum diterapkannya sistem komputerisasi pada bidang bisnis ini, maka pembuatan laporan penjualan menjadi berulang-ulang yang seharusnya cukup dikerjakan satu kali saja, hal ini sering menyebabkan terjadinya kesalahan dalam rekapitulasi penjualan, dan laporan data barang yang terjual.

Sistem informasi penjualan yang dibangun menggunakan VB.Net sebagai bahasa pemrogramannya serta MySQL sebagai basis datanya. Dalam hal deployment aplikasi VB.Net lebih mudah tinggal menyalin dari satu folder ke folder yang lain, sedangkan MySQL memiliki interface yang mudah dengan aplikasi dan bahasa pemrograman, serta banyak client dan tools yang dapat digunakan dalam mengelola database. Sistem informasi penjualan yang dihasilkan dapat memberikan solusi terhadap masalah yang ada pada sistem yang digunakan oleh bidang bisnis ini. Penelitian dimaksudkan agar sistem informasi yang dibangun dapat memberikan informasi penjualan yang lebih cepat dan akurat bagi pengguna, baik di level operasional maupun di level manajemen sehingga dapat membantu manajemen dalam pengambilan keputusan.

\section{TINJAUAN PUSTAKA}

Penelitian yang dilakukan oleh Muhammad, Punjar Sangaji dan Aminuddin Wicaksono menghasilkan sistem baru bagi UD. Indah Jati Sport Godean dalam pengolahan data penjualan dan persediaan barang, sehingga informasi dapat diperoleh dengan cepat dan efisien. Pembangunan sistem informasi ini menggunakan Visual Basic 6.0 dan SQL Server 2000 sebagai basis datanya [1]

Penelitian lainnya adalah Adi Nugroho dalam penelitiannya rancangan sistemnya menggunakan visual basic sedangkan rancangan basis datanya menggunakan Microsoft Access [2]

Penelitian lainnya Fendi, Maryanto dan Suwirno Mawlan dalam penelitiannya menggunakan metodologi berorientasi objek [3]. Sistem informasi ini ditujukan untuk dapat membantu direktur perusahaan tersebut dalam perencanaan dan pengendalian perusahaan, yaitu dapat menyediakan informasi yang dibutuhkan. Perancangan sistem informasi ini menggunakan VB.Net sebagai bahasa pemrogramannya sedangkan basis datanya menggunakan SQL Server 2005.

\section{METODE PENELITIAN}

\subsection{Analisis Sistem yang Berjalan}

Peneliti melakukan observasi pada CV. CINTEK untuk memahami sistem yang sudah berjalan. Hal ini dilakukan agar peneliti mengetahui kebutuhankebutuhan yang harus dipenuhi pada sistem yang akan dirancang. Hal ini dilakukan agar dapat mengurangi masalah bahkan menyelesaikan masalah yang terjadi melalui aplikasi sistem informasi yang baru. Pada tahapan ini dilakukan analisis terhadap yang sedang berjalan dan menguraikan kriteria sistem yang diusulkan melalui perbaikan dengan menggunakan metode analisis PIECES.

Metode PIECES adalah metode yang digunakan untuk mengidentifikasi masalah terhadap sistem lama yaitu (Performance, Information, Economy, Control, Efficiency, dan Service). Penyajian kelemahan sistem sebelumny dapat terlihat pada table di bawah ini.

Tabel 1. Analisis kelemahan sistem

\begin{tabular}{|c|c|c|}
\hline Jenis Analisis & $\begin{array}{c}\text { Kelemahan } \\
\text { Sistem Lama }\end{array}$ & $\begin{array}{c}\text { Sistem Yang } \\
\text { Diajukan }\end{array}$ \\
\hline Performance & $\begin{array}{l}\text { Pembuatan } \\
\text { laporan penjualan } \\
\text { oleh akuntan dan } \\
\text { keuangan masih } \\
\text { secara manual } \\
\text { atau } \\
\text { konvensional. }\end{array}$ & $\begin{array}{l}\text { Sistem Informasi } \\
\text { dapat membuat } \\
\text { pekerjaan menjadi } \\
\text { lebih cepat dan tidak } \\
\text { ada pekerjaan yang } \\
\text { berulang seperti } \\
\text { double pencatatan } \\
\text { saat pembuatan } \\
\text { laporan. }\end{array}$ \\
\hline Information & $\begin{array}{l}\text { Informasi yang } \\
\text { dihasilkan hanya } \\
\text { laporan } \\
\text { penjualan. Dan } \\
\text { pemrosesan } \\
\text { informasi } \\
\text { membutuhkan } \\
\text { waktu yang lama. }\end{array}$ & $\begin{array}{l}\text { Sistem menghasilkan } \\
\text { laporan penjualan, } \\
\text { laporan barang } \\
\text { terjual, laporan } \\
\text { piutang pelanggan, } \\
\text { dan laporan aging } \\
\text { piutang. }\end{array}$ \\
\hline
\end{tabular}




\begin{tabular}{|c|c|c|}
\hline Jenis Analisis & $\begin{array}{l}\text { Kelemahan } \\
\text { Sistem Lama }\end{array}$ & $\begin{array}{l}\text { Sistem Yang } \\
\text { Diajukan }\end{array}$ \\
\hline Economy & $\begin{array}{l}\text { Mengurangi } \\
\text { pendapatan } \\
\text { perusahaan, } \\
\text { karena terdapat } \\
\text { selisih jumlah } \\
\text { penjualan dalam } \\
\text { penghitungan } \\
\text { bulanan dengan } \\
\text { catatan barang } \\
\text { terjual yang tidak } \\
\text { tercatat. }\end{array}$ & $\begin{array}{l}\text { Dalam jangka pendek } \\
\text { pengadaan sistem } \\
\text { akan mengeluarkan } \\
\text { biaya yang besar } \\
\text { namun dalam jangka } \\
\text { panjang akan } \\
\text { memberikan manfaat } \\
\text { yang besar pula. }\end{array}$ \\
\hline Control & $\begin{array}{l}\text { Belum ada } \\
\text { keamanan dalam } \\
\text { penyimpanan } \\
\text { data, semua pihak } \\
\text { internal dalam } \\
\text { perusahaan dapat } \\
\text { mengakses. }\end{array}$ & $\begin{array}{l}\text { Dibuatkan hak akses } \\
\text { antara pihak-pihak } \\
\text { internal yang } \\
\text { berkepentingan } \\
\text { dengan data } \\
\text { keuangan } \\
\text { perusahaan. } \\
\text { Meminimalisir } \\
\text { pengambilan data } \\
\text { secara pribadi dan } \\
\text { memaksimalkan } \\
\text { pengendalian } \\
\text { internal. }\end{array}$ \\
\hline Eficiency & $\begin{array}{l}\text { Banyak waktu } \\
\text { yang terbuang } \\
\text { pada aktivitas } \\
\text { pembuatan } \\
\text { laporan. }\end{array}$ & $\begin{array}{l}\text { Tidak melakukan } \\
\text { penginputan lebih } \\
\text { dari satu kali untuk } \\
\text { data dan laporan } \\
\text { yang sama. } \\
\end{array}$ \\
\hline Services & $\begin{array}{l}\text { Pencatatan tidak } \\
\text { akurat, masih } \\
\text { terjadi kesalahan. }\end{array}$ & $\begin{array}{l}\text { Sistem menghasilkan } \\
\text { produk yang akurat } \\
\text { dan mudah dipelajari, } \\
\text { serta lebih } \\
\text { mempercepat dalam } \\
\text { pencatatan dan } \\
\text { pelaporan. }\end{array}$ \\
\hline
\end{tabular}

\subsection{Analisis Sistem Yang Berjalan}

Dari hasil analisis kelemahan sistem di atas, dapat disimpulkan bahwa beberapa kebutuhan fungsional mampu mengelola penjualan secara lebih cepat, tepat, dan akurat, serta pelaporan yang mudah dipahami manajemen guna pengambilan keputusan.

\subsection{Perancangan Sistem Informasi}

Berikut Data Flow Diagram (DFD) yang peneliti usulkan :

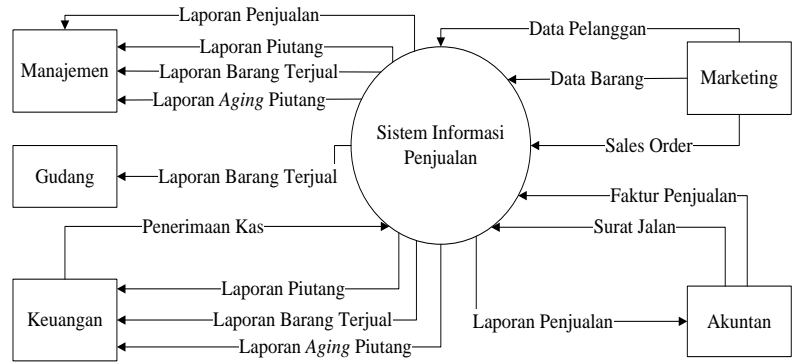

Gambar 1. Context diagram sistem informasi yang diusulkan.

\section{Keterangan Gambar :}

a. Sumber dan tujuan:

Marketing : Entitas yang melakukan input data barang, dan sales order.

Akuntan : Entitas yang melakukan input faktur penjualan dan surat jalan.

Keuangan : Entitas yang melakukan input penerimaan kas dan menerima laporan.

Manajemen : Entitas yang hanya menerima laporan.

Gudang : Entitas yang hanya menerima laporan.

b. Arus data:

Data pelanggan : meliputi nomor identitas pelanggan, nama pelanggan, alamat pelanggan, kontak pelanggan.

Data Barang : meliputi kode barang, nama barang, satuan dan harga satuan.

Sales Order : meliputi nomor sales order, kode pelanggan, nama pelanggan, alamat pelanggan, tanggal order kode barang, nama barang, satuan, harga satuan, jumlah barang, dan total.

Faktur Penjualan : meliputi nomor faktur, tanggal faktur, nomor sales order, tanggal order, tanggal jatuh tempo, kode pelanggan, nama pelanggan, alamat pelanggan, kode sales, diskon, kode barang, nama barang, satuan, harga satuan, jumlah barang dan total.

Surat Jalan : meliputi nomor surat jalan, tanggal surat jalan, kode pelanggan, nama pelanggan, alamat pelanggan, kode barang, nama barang, satuan, dan jumlah barang.

Penerimaan Kas: meliputi nomor faktur, nomor bukti kas masuk, tanggal bayar, total piutang, pembayaran dan sisa.

c. Laporan:

1. Laporan penjualan berupa laporan transaksi penjualan.

2. Laporan barang terjual berisi rekapan barang yang terjual.

3. Laporan piutang berisi piutang yang timbul dari transaksi penjualan kredit.

4. Laporan aging piutang merupakan laporan yang berisi perputaran piutang pelanggan sebagai laporan bagi manajemen. 


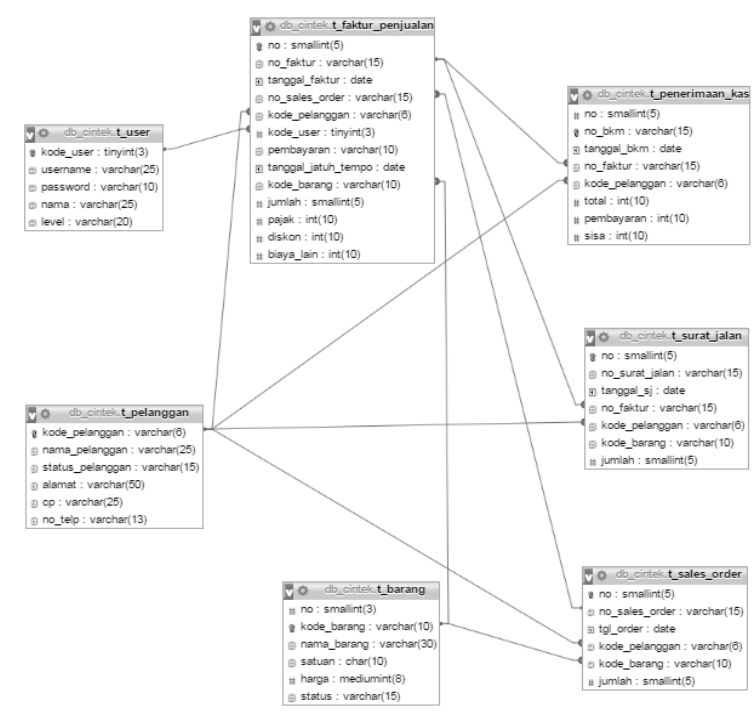

Gambar 2. Relasi antar tabel

Tabel 2. Fungsi Tabel pada Database

\begin{tabular}{|c|c|c|}
\hline No. & Nama Tabel & Deskripsi Fungsi \\
\hline 1 & t_user & $\begin{array}{ll}\text { Menyimpan } & \text { data } \\
\text { pengguna } & \text { pada }\end{array}$ \\
\hline 2 & t_barang & $\begin{array}{l}\text { Menyimpan master } \\
\text { data barang yang } \\
\text { disajikan dalam data } \\
\text { grid view sales order, }\end{array}$ \\
\hline 3 & t_pelanggan & $\begin{array}{l}\text { Menyimpan master } \\
\text { data pelanggan yang } \\
\text { disajikan dalam form } \\
\text { sales order, faktur }\end{array}$ \\
\hline 4 & $\mathrm{t} \_s a l e s \_o r d e r$ & $\begin{array}{lr}\text { Menyimpan } & \\
\text { informasi } & \text { pesanan } \\
\text { pelanggan } & \text { yang } \\
\text { diinput dalam } & \text { form }\end{array}$ \\
\hline 5 & t_faktur_penjualan & $\begin{array}{l}\text { Menyimpan } \\
\text { informasi faktur } \\
\text { penjualan yang } \\
\text { diinput dalam form } \\
\text { faktur penjualan }\end{array}$ \\
\hline 6 & t_surat_jalan & $\begin{array}{l}\text { Menyimpan } \\
\text { informasi surat jalan } \\
\text { yang diinput dalam } \\
\text { form surat jalan yang }\end{array}$ \\
\hline 7 & t_pembayaran & $\begin{array}{l}\text { Menyimpan } \\
\text { informasi }\end{array}$ \\
\hline
\end{tabular}

\subsection{Perancangan Sistem Informasi}

Implementasi dilakukan setelah tahap perancangan sistem secara rinci, kemudian diimplementasikan ke dalam bahasa pemrograman. Dalam implementasi pada aplikasi sistem informasi penjualan, data yang dimasukkan meliputi data barang, data pelanggan, sales order ,faktur penjualan, surat jalan dan pembayaran dimana data tersebut akan diproses oleh sistem hingga menjadi suatu laporan yang terdiri dari laporan penjualan, laporan barang terjual, laporan piutang pelanggan dan laporan aging piutang. Adapun implementasi tersebut meliputi implementasi perangkat keras, implementasi perangkat lunak, implementasi database dan implementasi antarmuka pengguna dan laporan.

Implementasi antarmuka pengguna (user interface) dibuat berdasarkan analisis kelemahan sistem berjalan dan analisis kebutuhan sistem. Adapun tampilan dari implementasi antarmuka pengguna adalah sebagai berikut:

\section{a. Form Login}

Setiap pengguna (user) melakukan login untuk dapat mengakses semua menu yang ada pada halaman menu utama. Saat user melakukan login, sistem akan melakukan pengecekan nama pengguna dan kata sandi. Jika sistem dapat menerima data yang diinputkan pada form login tersebut, maka form menu utama dapat diakses, jika tidak sesuai maka aplikasi tidak dapat digunakan. Pengujian ini dilakukan untuk mengetahui sejauh mana tingkat keamanan sistem yang telah dibuat.

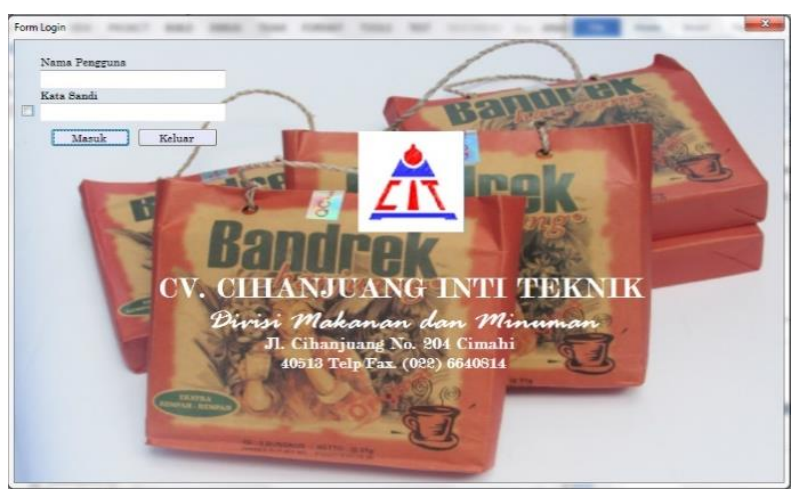

Gambar 3. Implementasi Form Login

\section{b. Form Menu Utama}

Halaman ini berfungsi sebagai sarana untuk masuk ke sub-sub menu. Adapun yang menjadi menu dari tampilan menu utama adalah menu "File" yang di dalamnya terdapat sub menu "Ubah Password" dan sub menu "Keluar" untuk keluar dari aplikasi ini. Menu "Entri Data" yang memiliki sub menu "Data Pelanggan", "Daftar Harga Barang", dan "Entri User." Menu "Transaksi" yang berisi sub menu "Sales Order", "Faktur Penjualan", "Surat Jalan" dan "Pembayaran". Menu "Laporan" berisi sub menu "Penjualan", "Barang Terjual", "Piutang Pelanggan" dan "Aging Piutang". Menu "About" berisi informasi sistem informasi 
penjualan. Pada menu utama hanya "level admin" yang dapat mengakses semuanya, dan selain daripada admin hanya akan dapat mengakses sesuai dengan level atau jabatannya.

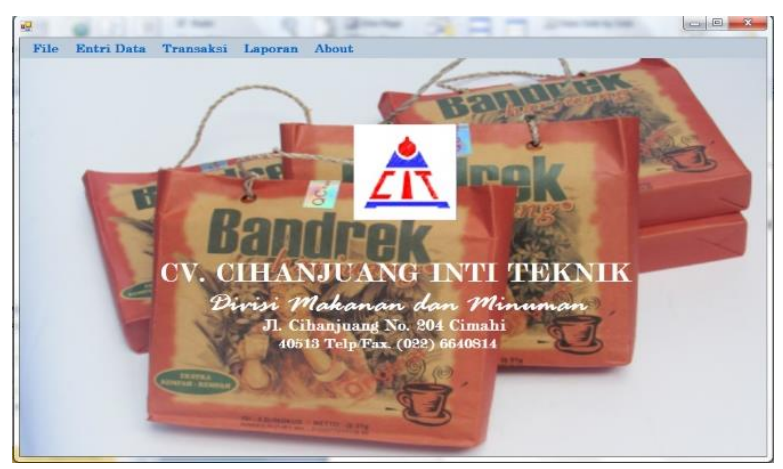

Gambar 4. Implementasi Form Menu Utama

\section{c. Laporan Penjualan}

Laporan penjualan adalah kumpulan data penjualan tunai dan kredit secara periode, yang berfungsi untuk melihat total penjual pada periode yang diinginkan. Laporan penjulan ini berisi nomor faktur, tanggal faktur, kode pelanggan, nama pelanggan, kode barang, nama barang, qty, satuan, harga satuan, sub total, grand total, dan jenis pembayaran tunai atau kredit, dan tanggal serta waktu cetak laporan.

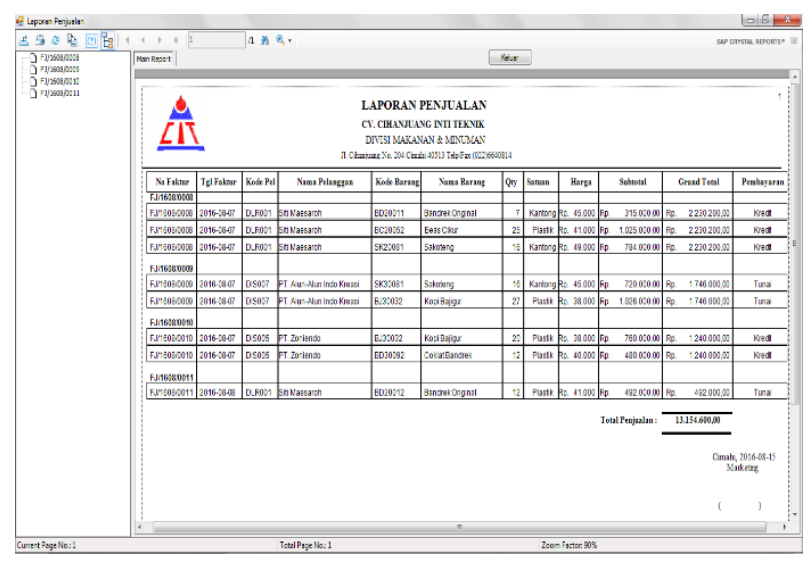

Gambar 5. Implementasi Laporan Penjualan

\section{d. Laporan Barang Terjual}

Laporan barang terjual adalah rekapitulasi jumlah barang yang terjual berdasarkan periode yang diinginkan, untuk dicocokkan dengan jumlah barang yang keluar dari gudang. Laporan barang terjual ini berisi kode barang, nama barang, status pelanggan, satuan, harga, jumlah yang terjual, tanggal terjual, serta tanggal dan waktu cetak laporan.

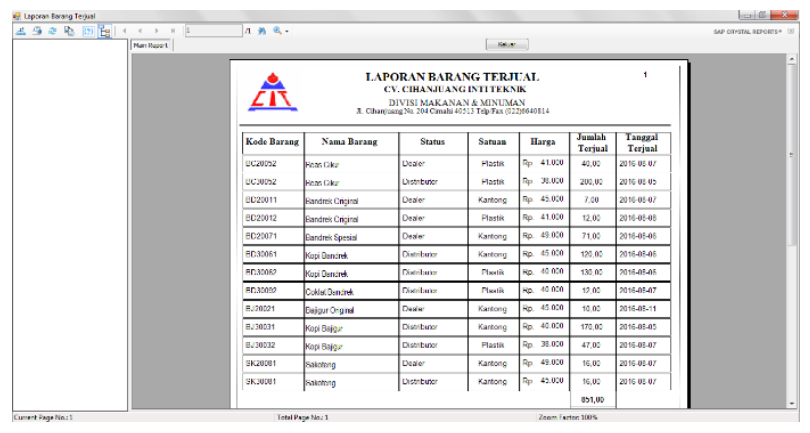

Gambar 6. Implementasi Laporan Barang Terjual

\section{e. Laporan Piutang}

Laporan piutang adalah rekapitulasi transaksi penjualan secara kredit beserta nominal piutang pelanggan yang dicetak berdasarkan periode. Laporan piutang berisi nama pelanggan, nomor faktur, tanggal faktur, total piutang, cara bayar, nama sales serta tanggal dan waktu cetak laporan.

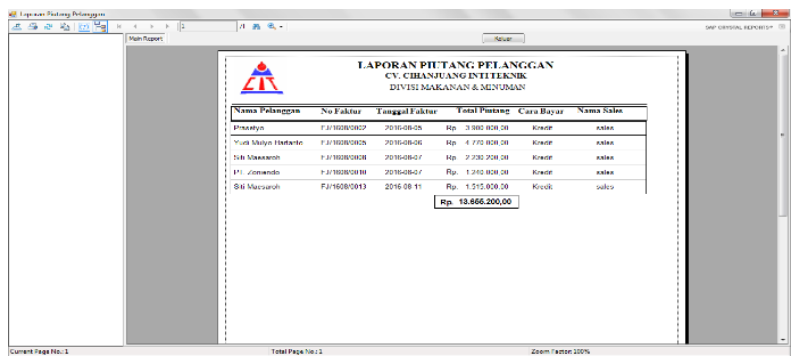

Gambar 7. Implementasi Laporan Piutang Pelanggan

\section{f. Laporan Aging Piutang}

Laporan aging piutang adalah informasi daftar piutang pelanggan dan pembayarannya, yang bertujuan untuk mengetahui disiplin pelanggan dalam membayar utang serta menjadi sumber kebijakan bagi manajemen dalam pengambilan keputusan. Selain itu laporan ini juaga dapat menjadi daftar penagihan piutang kepada pelanggan yang akan segera jatuh tempo. Laporan aging piutang berisi nama pelanggan, nomor faktur, sub total, diskon, pajak, total bayar, tanggal faktur, tanggal jatuh tempo, tanggal bayar, dan jumlah telat, tanggal dan waktu cetak laporan. 


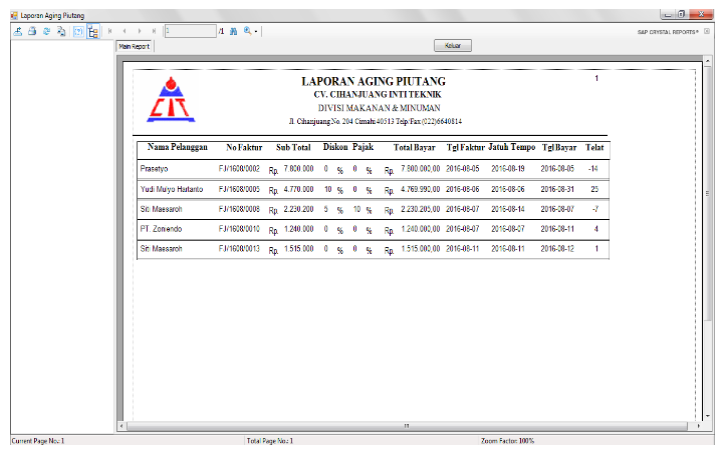

Gambar 8. Implementasi Laporan Aging Piutang

\section{HASIL DAN PEMBAHASAN}

\subsection{Pengujian Sistem}

Pengujian sistem bertujuan untuk mengetahui sistem informasi yang dibuat sudah memenuhi kriteria yang sesuai dengan tujuan dan perancangan sistem informasi yang dibuat. Tahap pengujian sistem diawali dengan tahap rencana pengujian dan dilanjut dengan tahap pengujian sistem. Dalam pengujian sistem informasi penjualan pada $\mathrm{CV}$. CINTEK ini peneliti menggunakan dua metode yakni dengan melalui pengujian menggunakan alfa (blackbox) dan menggunakan pengujian beta (kuesioner).

\subsection{Pengujian Sistem}

Berdasarkan hasil pengujian sistem yang dilakukan pada pengguna aplikasi sebanyak lima responden dengan menggunakan kuesioner maka secara garis besar peneliti menyimpulkan bahwa aplikasi yang telah dibuat sudah cukup baik sesuai dengan kebutuhan pada perusahaan, selain itu berdasarkan perhitungan pada kuesioner aplikasi yang dibuat memiliki kelebihan dalam menghasilkan informasi yang sesuai dengan kebutuhan, dengan tingkat kepuasan sebesar 100\%. Sedangkan kelemahan dari sistem ada pada pernyataan bahwa aplikasi dapat menyajikan informasi yang detail dan akurat, dengan tingkat kepuasan sebesar $88 \%$.

Kesimpulan dari pembahasan di atas disajikan dalam tabel berikut ini :

Tabel 3. Deskripsi Laporan

\begin{tabular}{lll}
\hline No. & Nama Tabel & Deskripsi Fungsi \\
\hline 1. & Laporan & Kumpulan data penjualan \\
& Penjualan & tunai dan kredit dari \\
& & pelanggan selama periode, \\
& & untuk mengetahui total \\
& & penjualan pada periode \\
& & laporan yang diinginkan. \\
\hline
\end{tabular}

\begin{tabular}{|c|c|c|}
\hline No. & Nama Tabel & Deskripsi Fungsi \\
\hline 2. & $\begin{array}{l}\text { Laporan } \\
\text { Barang Terjual }\end{array}$ & $\begin{array}{l}\text { Rekapitulasi data barang } \\
\text { yang terjual untuk } \\
\text { dicocokkan dengan jumlah } \\
\text { barang yang keluar dari } \\
\text { gudang. }\end{array}$ \\
\hline 3. & $\begin{array}{l}\text { Laporan } \\
\text { Piutang }\end{array}$ & $\begin{array}{l}\text { Rekapitulasi } \text { transaksi } \\
\text { penjualan secara } \\
\text { beserta nominal piutang } \\
\text { pelanggan yang dicetak } \\
\text { berdasarkan periode. }\end{array}$ \\
\hline 4. & $\begin{array}{l}\text { Laporan Aging } \\
\text { Piutang }\end{array}$ & $\begin{array}{lr}\text { Informasi daftar piutang } \\
\text { pelanggan }\end{array}$ \\
\hline
\end{tabular}

Adapun yang menjadi menu dari tampilan menu utama adalah menu "File" yang di dalamnya terdapat sub menu "Ubah Password" dan sub menu "Keluar" untuk keluar dari aplikasi ini. Menu "Entri Data" yang memiliki sub menu "Data Pelanggan", "Daftar Harga Barang", dan "Entri User". Menu "Transaksi" yang berisi sub menu "Sales Order", "Faktur Penjualan", "Surat Jalan" dan "Pembayaran". Menu "Laporan" berisi sub menu "Penjualan", "Barang Terjual", "Piutang Pelanggan" dan "Aging Piutang". Menu "About" berisi Informasi sistem informasi penjualan, bahwa aplikasi tersebut membuat pekerjaan menjadi lebih efektif dan efisien.

\section{KESIMPULAN}

Beberapa hal yang dapat penulis simpulkan dari hasil penelitian yang dilakukan pada CV. CINTEK :

Proses transaksi penjualan pada CV. CINTEK masih menggunakan pembukuan pencatatan manual dan menggunakan Microsoft Office Excel 2007. Analisis sistem informasi yang penulis temukan pada $\mathrm{CV}$. CINTEK merupakan proses transaksi dalam kegiatan penjualan masih menggunakan pembukuan atau pencatatan manual dan pembuatan laporan dilakukan secara berulang dimulai dari laporan penjualan harian, mingguan dan bulanan yang biasanya dikerjakan selama tiga sampai empat hari.

Perancangan sistem informasi ini meliputi : perancangan $D F D$, perancangan database dengan menggunakan normalisasi data, ERD, serta perancangan User Interface.

Implementasi sistem informasi yang dibuat peneliti menghasilkan sistem informasi penjualan yang sudah dapat melakukan pengolahan data secara computerized. 
Hasil dari pengujian alpha yang menunjukan aplikasi yang telah dibuat sesuai dengan kebutuhan dan telah memenuhi persyaratan fungsional. Dari hasil pengujian beta yang dilakukan di perusahaan berupa pemberian kuesioner kepada calon pengguna menunjukan hasil pengujian tersebut dikatakan sudah baik untuk sistem yang telah dibuat dan diujikan di perusahaan.

\section{DAFTAR PUSTAKA}

[1] Muhammad, P. Sangaji, and A. Wicaksana, "Analisis dan Perancangan Sistem Informasi Penjualan dan Persediaan Barang Pada UD. Indah Jati Sport," 2010.

[2] A. Nugroho, "Perancangan Dan Implementasi Sistem Penjualan Pada Sapari Bike Shop Menggunakan Visual Basic," no. 5, 2014.

[3] Fendi, Maryanto, and S. Mawlan, “Analisis Dan Perancangan Sistem Informasi Manajemen Penjualan Spare Part Menggunakan Metodologi Berorientasi," pp. 1-6, 2013. 